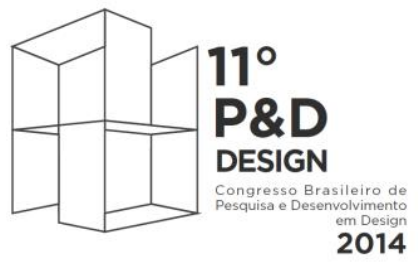

$$
\text { Gramado - RS }
$$

De 30 de setembro a 2 de outubro de 2014

\title{
INOVAÇÃO GUIADA PELO DESIGN: possíveis caminhos para pensar a significação em produtos e serviços
}

Design-driven Innovation: possible ways to think about the meaning of products and services

Roncalio, Vanessa Weiss; mestranda; Universidade Federal do Paraná

vroncalio@yahoo.com

Kistmann, Virgínia Borges; Doutora; Universidade Federal do Paraná

vkistmann@ufpr.br

Resumo: Este artigo discute os conceitos da inovação guiada pelo design, que propõe a geração de novos significados para produtos. Trata-se de um estudo exploratório, apoiado em teorias das áreas de design e de marketing que traz como resultado uma categorização de significação visando um maior entendimento da abrangência da inovação de significado e das possíveis associações aos produtos e serviços que serão disponibilizados aos consumidores. Em suma, recomenda-se buscar o entendimento e o alinhamento das categorias de significados para a elaboração de estratégias coesas e consistentes, estabelecendo alguns critérios para estudos futuros.

Palavras-chave: gestão de design, inovação guiada pelo design, design de produtos e serviços, categorias de significação.

Abstract: This paper discusses the concepts of design-driven innovation which proposes the creation of new meanings for products. This is an exploratory study supported by theories in the areas of design and marketing. As a result, we propose a categorization of meaning aiming at a better understanding of the scope of innovation of meaning and potential associations with products and services that will be available to consumers. In short, we recommend the understanding and the alignment of the categories of meanings for the development of cohesive and consistent strategies, establishing some criteria towards future studies.

Keywords: design management, design-driven innovation, product and service design, categorization of meaning. 


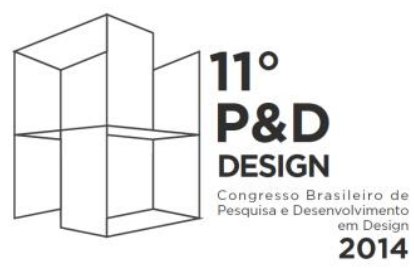

Gramado - RS

De 30 de setembro a 2 de outubro de 2014

\section{INTRODUÇÃO}

O sucesso de grandes empresas orientadas pelo design tem motivado a discussão de como ocorre a inovação que gera vantagem competitiva no mercado (WALSH et al. 1992; VERGANTI, 2012a; MUTLU, ER, 2013). Nesse contexto, atualmente, diversas classificações e modelos de inovação, sejam em produtos, serviços ou processos, estão difundidos na literatura do design e de sua gestão. Com isso, o papel do design vem se ampliando, deixando de ser reconhecido apenas por inovações incrementais em estilo, passando a um conceito de inovação bem mais abrangente (ibid.).

Discussões acerca da importância do papel do design para a inovação vêm das áreas de administração, marketing e P\&D (WALSH et al., 1992). Admitindo essa contribuição, o Department for Business, Innovation and Skills e o NESTA do Reino Unido incluíram o design em seus relatórios na categoria de investimento em "capital intangível" para a inovação (DONG, 2013). Ou seja, o valor integrador e estratégico do design para a inovação é cada vez mais reconhecido (BEVERLAND; FARREL, 2007 apud LINDAHL; GRUNDSTRÖM, 2012).

Nesse sentido, atualmente, as atenções se voltam para uma abordagem que considera novas proposições de significados dos produtos (VERGANTI, 2012a). O conceito-chave de Verganti trata da mudança radical do significado de um produto ou serviço. Assim, pensar no significado de um produto conduz à investigação do tipo de experiência que as pessoas poderiam desejar, partindo de pesquisas mais aprofundadas sobre tendências socioculturais, estilos de vida e evolução tecnológica.

Em relação à ampliação do papel do design nos processos de inovação de produto, Verganti e Öberg (2013) acrescentam que a gestão da inovação tem focado na mudança radical de tecnologias, enquanto as dinâmicas da mudança radical de significado têm sido pouco exploradas. Segundo os autores, um motivo para esta falta de investigação é que a natureza da inovação de significado é bastante peculiar, envolvendo fatores simbólicos, emocionais e intangíveis. Eles ainda argumentam que as teorias clássicas da inovação, foram concebidas principalmente para a inovação de fatores tangíveis como tecnologia, utilidade, desempenho e função, e, portanto, novas abordagens e referências são necessárias (VERGANTI; ÖBERG, 2013).

Nesse estudo são destacados os modelos de inovação de significado de produto ou de serviço pela ótica da "inovação guiada pelo design" a partir da análise da literatura de design e de marketing. Como resultado, propõe-se uma categorização para se pensar a significação em produtos. O principal desafio é buscar métodos apropriados, pelos quais futuros significados possam ser incorporados aos projetos. Assim, é necessário expor de que maneira os significados podem estar associados aos 


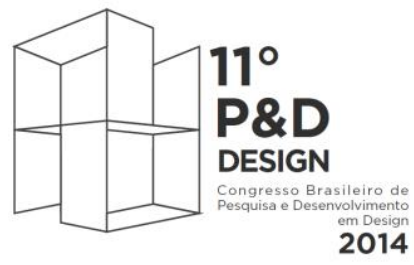

Gramado - RS

De 30 de setembro a 2 de outubro de 2014

produtos e serviços que serão disponibilizados aos consumidores e que critérios podem ser a eles estabelecidos.

\section{Principais conceitos e terminologias: design $x$ inovação}

Primeiramente, convém esclarecer os termos mais utilizados na literatura, já que estes muitas vezes se confundem. De um modo geral, os termos citados a seguir se referem à prática do design como um meio para se chegar a um resultado inovador em produtos e serviços. Em parênteses são indicados alguns autores que mencionam as expressões em seus trabalhos, o que não necessariamente indica que esses foram cunhados pelos mesmos.

O termo "inovação orientada pelo design" (design-led innovation) (BEVERLAND \& FARELLY, 2007; KYFFIN, GARDIEN, 2009) é considerado o termo mais abrangente, sinônimo dos termos: "inovação através do design" (innovation through design) (VERGANTI, 2006), "inovação pelo design" (innovation by design) (MUTLU et al., 2003), e "inovação inspirada pelo design" (design inspired innovation) (UTTERBACK et al. 2007). Dessa forma, "inovação orientada pelo design" parece ser o termo mais utilizado para descrever uma ampla gama de atitudes e ações relacionadas ao design, que uma empresa estabelece como meta estratégica para diferenciação e inovação. Segundo Dong (2013), essas ações que promovem o design incluem: metodologias e ferramentas do design, características individuais dos designers, cultura e estratégia empresarial além da busca por novos significados (DONG, 2013, p. 07).

Por sua vez, a expressão "inovação guiada pelo design" (design-driven innovation) (VERGANTI, 2012) refere-se à inovação radical de significado dos produtos. Este termo caracteriza, segundo o autor, a maneira mais marcante para o design ser reconhecido como vetor da inovação, sendo que este último termo, por vezes, é substituído por meaning-driven innovation (BAHA et al. 2013). Neste trabalho, utilizase o termo "inovação guiada pelo design" por essas características.

\section{Antecedentes do estudo da inovação de significado no design}

$O$ estudo de novas proposições de significados em produtos e serviços tem antecedentes na literatura de design, referente à semântica de produto; e também na literatura de administração e de marketing, no que se refere à proposição de novos valores a serem ofertados aos consumidores.

\subsection{Semântica de produtos}

A expressão "semântica de produto" baseada em teorias linguísticas ganhou força nos Estados unidos nos anos 80 causando grande impacto com essa nova 


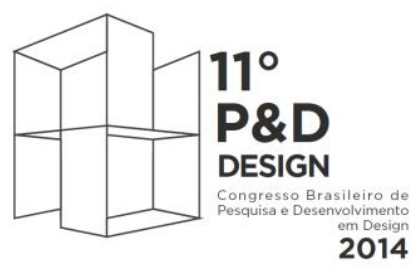

Gramado - RS

De 30 de setembro a 2 de outubro de 2014

concepção de design (BÜRDEK, 2010). Este conceito, de um modo geral, tem origem na semiótica que já era aplicada em produtos na HfG de Ulm (ibid).

Ela é definida por Krippendorff como o estudo das qualidades simbólicas dos artefatos em seu contexto de uso e a aplicação desse conhecimento no design (KRIPPENDORFF, 1984). É um estudo aprofundado dos significados que emergem na interação humana com os objetos de uso. Segundo o autor, é através da semântica de produto que os designers podem desmistificar uma tecnologia complexa, ou aprimorar a interação dos artefatos com seus usuários e ainda ampliar oportunidades para expressar a auto-imagem dos usuários (ibid). Destaca que, se o significado de um objeto não está claro para nós, nos sentimos impelidos a explorá-lo até que consigamos compreendê-lo. É por este motivo que o significado de algo não reside em sua superfície, mas emerge com o uso, através de nossas ações e percepções adquirindo experiência de acordo com cada contexto de uso (KRIPPENDORFF, 1990). Dessa forma, o estudo da semântica deve concentrar em buscar o que é significativo e motivador para os seres humanos (ibid).

Para esse autor, uma diferença importante deve ser estabelecida entre significado e sentido dos objetos, pois são duas maneiras distintas de relação com os objetos. Algo faz sentido quando compreendemos o papel que um objeto cumpre em determinado contexto, quando se tem uma explicação satisfatória para isso. Já o significado de um objeto é a soma total de todos os contextos nos quais alguém é capaz de imaginar algum sentido para esse objeto. O que possibilita alguém antecipar possíveis contextos de uso. Assim, o significado traz consigo uma potencialidade de realização. Em suma, adquirimos o significado de algo generalizando em uma série de contextos a variedade de sentidos que poderíamos obter do objeto (KRIPPENDORFF, 1990). Portanto, a teoria da semântica também possibilita entender a proposição de novos significados para os produtos.

\subsection{A proposição de valor ou de novos significados no marketing}

Esses conceitos referentes a explicitar (por parte do usuário) ou criar (por parte do fabricante) a demanda por algo ainda inexistente no mercado também tem origem na literatura de administração e de marketing (VON HIPPEL, 1994; HAMEL, 2000; MARZANO, 1988 apud BRASIL, RITTO, 2000). Assim, pode-se falar de "sensitividades latentes" (MARZANO, 1988 apud BRASIL, RITTO, 2000) a partir da percepção a respeito de produtos ou serviços que os usuários poderiam desejar. Também pode se falar da inovação de valor, na qual KIM \& MAUBORGNE $(1999,2005)$ utilizam uma metáfora para ilustrar a necessidade de criar "oceanos azuis" em um nicho de mercado onde os concorrentes ainda operam nas áreas saturadas, os chamados "oceanos vermelhos" 


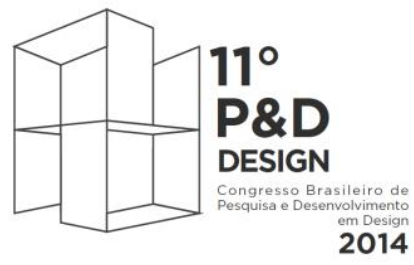

Gramado - RS

De 30 de setembro a 2 de outubro de 2014

(KIM, MAUBORGNE, 1999, 2005 apud BOABAID, 2006). Em resumo, são conceitos similares para expressar a necessidade de atender a desejos subjetivos e latentes dos consumidores.

Na perspectiva do marketing, Kotler \& Keller (2006) propuseram os conceitos de benefício central e produto ampliado, onde cada nível agregaria maior valor percebido pelo cliente, buscando estabelecer uma hierarquia de valor. Com a seguinte classificação: Nível 1- Benefício central: o benefício fundamental que o cliente adquire; Nível 2- Produto básico: A versão básica de um produto; Nível 3- Produto esperado: expectativas mínimas em relação ao produto; Nível 4- Produto ampliado: excede as expectativas com o posicionamento de marca, a competição se acentua neste nível; Nível 5- Produto potencial: abrange todas as ampliações e transformações que o produto pode ser submetido no futuro. Nessa abordagem do marketing, o papel do design se refere, sobretudo, aos aspectos mais tangíveis, correspondentes ao produto básico.

\subsection{Inovação guiada pelo design}

Já nas últimas décadas do século passado, a importância da significação ganha crescente relevância no desenvolvimento de projeto de sistemas de uso e nos sistemas de informação: "[...] não basta algo ser formalmente agradável, ser funcional, prover uma boa interface. É mister também o produto portar a mensagem adequada, "dizer" o que se pretende para quem interessa" (NIEMEYER, 2013, p.18).

De acordo com Verganti (2012b) as pessoas não usam produtos e serviços pensando apenas na sua utilidade, mas por razões emocionais, psicológicas e socioculturais (VERGANTI, 2012b). Conforme seu ponto de vista, as empresas que são realmente inovadoras adotam uma perspectiva mais ampla imaginando um novo contexto. Ou seja, ao invés de focarem no produto, se perguntam: "de que tipo de experiência as pessoas gostariam?" (VERGANTI, 2012b, p.1). O autor conclui que os produtos sempre tiveram uma dupla natureza: o aspecto utilitário e o aspecto simbólico. "A dialética não é, portanto, entre função e forma, mas entre função e significado" (VERGANTI, 2012a, p.28). Dessa forma, o autor ressalta o valor social e simbólico de um produto.

Para esclarecer o papel do design no processo de inovação, Verganti estabelece duas dimensões radicais de inovação: a tecnológica e a de significado, a partir de três vetores que iniciam este processo: tecnologia, design e mercado. Na maioria dos casos, a inovação é percebida como o avanço tecnológico (technology-push) ou como o resultado de pesquisas centradas no usuário (market-pull), que, segundo Verganti (2012a), esses dois tipos de inovação são complementares a outras: as guiadas pelo 


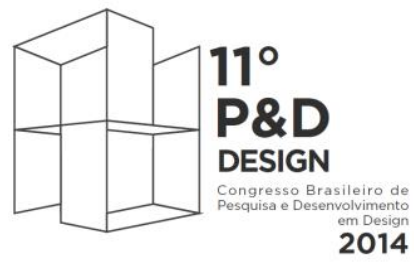

Gramado - RS

De 30 de setembro a 2 de outubro de 2014

significado (meaning-driven) e o que ele chama de epifanias tecnológicas (technology epiphanies), que utilizam novas ou conhecidas tecnologias em novos contextos. Segundo o autor, todos os modelos de inovação têm certa influência sobre os outros. Assim como a inovação empurrada pela tecnologia requer uma profunda compreensão das dinâmicas do mercado, também a inovação guiada pelo significado implica em analisar as aspirações dos usuários, explorando novas tecnologias. Assim, há um pouco de cada modelo de inovação em cada projeto de sucesso. O que é diferente é o que se considera como ponto de partida.

De acordo com Norman \& Verganti (2012), os tradicionais processos de ideação e métodos criativos não enfatizam suficientemente a importância dos processos interpretativos. As inovações radicais de significado se tornam possíveis a partir de pesquisas e observações dos sinais socioculturais, ao invés de focar apenas na criatividade sem rumo definido (ibid.). Dessa forma, a pesquisa em design deve ser direcionada a novas interpretações do que poderia ser significativo para as pessoas. Nesse sentido, corroboram as visões de Celaschi \& Deserti (2007 apud VIEIRA, 2007), pois as abordagens clássicas do processo de design se concentram mais nos aspectos tangíveis do produto, enquanto o contexto atual exige que se considerem outras dimensões, mais intangíveis como comunicação e experiência.

Portanto, se evidencia a necessidade de uma visão mais abrangente e flexível do processo de design adaptado ao contexto atual. É preciso incluir uma visão sistêmica que compreenda tanto os aspectos tangíveis como os intangíveis.

\section{Contribuição para uma categorização da significação em produtos}

A literatura recente, que discute a inovação guiada pelo design, apresenta diversas formas pelas quais se pode pensar em inovação de significado em produtos e serviços. São enfoques bem diferenciados: desde uma inovação de significado radical na utilização de um produto, passando pelas inovações em marketing, ou incluindo serviços adicionados aos produtos. Todas as propostas prometem mudar o enfoque dado aos produtos.

Sendo assim, este presente estudo propõe uma classificação para as diversas categorias de significação, no intuito de que as contribuições da literatura possam auxiliar na escolha de estratégias mais adequadas por parte das empresas. Nesta categorização, há similaridades com a classificação de Kotler \& Keller (2006), porém não há uma hierarquia de valor, ou seja, nesta proposta todas as categorias possuem atributos específicos que podem agregar significação e valor aos produtos. São elas:

1. Proposta central: o benefício mais evidente trazido pela experiência da posse ou do uso. 


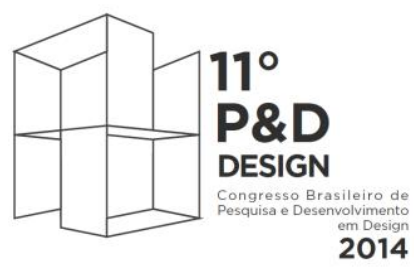

Gramado - RS

De 30 de setembro a 2 de outubro de 2014

2. Produto tangível: forma, cor, material, utilidade, embalagem, etc.

3. Produto-marca: branding, campanhas publicitárias em várias mídias, associações com personalidades, patrocínio de eventos, etc.

4. Produto-serviço: vendas diretas ou indiretas, experiência no atendimento, entrega, garantia, manutenção, instalação, créditos, serviços pós-compra, atenção ao ciclo de vida do produto, compartilhamento etc.

5. Produto interpretado/co-criado: interface com o consumidor, somando os significados intencionais sugeridos pela empresa às interpretações altamente subjetivas por parte do consumidor do produto e de toda experiência que o envolve. As associações são pessoais e subjetivas e não há controle direto sobre as interpretações a respeito da aparência ou da utilização de um produto, ou ainda da experiência de compra. Esta categoria corresponde também à possibilidade de co-criação de todas as categorias anteriores por parte do consumidor. A co-criação também acrescenta uma nova dimensão para a interpretação de um produto ou serviço que teve participação ativa do consumidor.

Observa-se que as primeiras quatro categorias de significados aqui propostas são definidas e sugeridas pelas empresas, em um contexto de produção. Porém, a quinta categoria corresponde à interpretação do consumidor de todas as categorias anteriores e se encontra, ao mesmo tempo, em um contexto de uso pela interação com o produto, mas em alguns casos, também se insere no contexto da produção, pela possibilidade de co-criação de um produto.

O estudo de Verganti (2012b) foca, sobretudo, nas duas categorias iniciais de significação em produtos. A contribuição do autor se deu pela maneira de destacar a conceituação da experiência de um produto, o que corresponde à proposta central, que uma vez definida, leva ao produto tangível que irá incorporar um novo conceito.

Com relação ao produto-marca, um bom exemplo da adição posterior de significado pode ser conferido pela associação do produto a um valor cultural específico. Um tipo de valor inteiramente imaterial, pois não está presente no objeto físico, mas esses aspectos comunicativos podem ser elementos tão importantes quanto às propriedades físicas dos objetos (HANSEN-HANSEN, 2012). Nesse sentido, é importante enfatizar a integração do design com o marketing, o que pode prover associações culturais por meio da promoção do produto em museus e exposições artísticas, por exemplo, para ganhar importância cultural na mente do consumidor (WALSH et al., 1992). Um bom exemplo desse tipo de significação conferida ao 


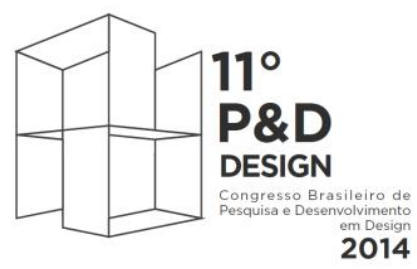

Gramado - RS

De 30 de setembro a 2 de outubro de 2014

produto-marca ocorre no campo da moda e na indústria de bens de luxo, onde os valores simbólicos são altamente significativos.

Por sua vez, Baha et al. (2013a) trazem uma importante contribuição ao investigar como os significados trazidos por certo produto são construídos ao longo do tempo. O objeto de estudo foi uma análise da evolução do material gráfico referente às capas de álbuns na indústria fonográfica. De acordo com os autores, qualquer proposta de novos significados em um produto deveria ser baseada em sua evolução histórica, pois, este tipo de análise conduz a uma compreensão mais ampla sobre os significados atuais e os significados que foram perdidos no tempo. Essa análise poderá ser utilizada, inclusive, para se descobrir significados latentes que poderiam ser reformulados. Assim, alguns destes significados anteriores, que ficaram no passado poderiam ser estudados e trazidos à tona novamente, em uma nova proposta central, atualizando-os em novos produtos tangíveis. Ao estudar a evolução de um produto, também se pode ter uma ideia mais clara não somente dos significados que se deseja propor, mas dos significados que se quer evitar; ou ainda, propor uma combinação entre significados já existentes e novas proposições (ibid.).

Em outro estudo, os autores supracitados (BAHA et al., 2013b) propõem o design de serviços para contribuir positivamente para a mudança de significados dos produtos. Aqui a estratégia se concentra na categoria de produto-serviço. Os autores realizaram um trabalho com uma empresa de vestuário holandesa juntamente com fabricantes de tricô artesanais do Equador e do Peru. Nesse estudo, os autores introduziram narrativas a respeito da fabricação do produto além de promover também a interação do consumidor com os produtores. Essas ações tiveram o intuito de contribuir para uma maior valorização dos produtos. Os autores concluíram que, unicamente através dos serviços adicionados, os consumidores interpretaram de maneira diversa um produto que em sua essência não havia sido redesenhado. No entanto, os autores recomendam mais estudos para uma melhor compreensão e utilização da abordagem adotada (ibid.).

Em busca de uma valorização de um trabalho mais ético, Kotler (2010) aborda a tendência crescente de a humanidade buscar mais valores espirituais, indicando que "os consumidores não estão buscando apenas produtos e serviços que satisfaçam suas necessidades, mas também buscando experiências e modelos de negócios que toquem seu lado espiritual. Proporcionar significado é a futura proposição de valor do marketing" (KOTLER et al., 2010, p.21). Essa abordagem, procura compartilhar valores e desejos com os consumidores, que podem participar do desenvolvimento de produtos, bem como atuar na comunicação (ibid). Nesse sentido, a estratégia da empresa deverá focar na inovação obtida através da interface com o consumidor, na categoria de produto interpretado/co-criado. 


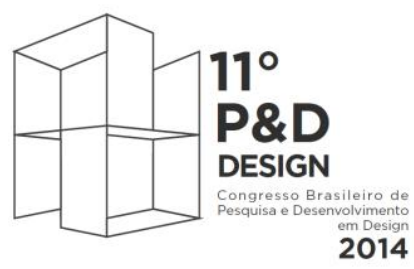

Gramado - RS

De 30 de setembro a 2 de outubro de 2014

Neste estudo destaca-se a função integradora do design para a significação total do produto, ou seja, "toda a cadeia de valor deve ter o potencial de ser orientada pelo design, desde o projeto de produto, ambiente de compra, propaganda, a disposição dos produtos e a embalagem até a promoção da co-produção de valor pelo consumidor" (HANSEN-HANSEN, 2012, p.616). Por sua vez, Borja de Mozota et al. (2011) corrobora com a visão de que a produção, o marketing e o design são todos responsáveis, dentro de uma empresa, pela criação e atribuição de "utilidade à forma" (BORJA DE MOZOTA et al., 2011). Até mesmo a experiência de consumo poderá influenciar a percepção geral do produto (ibid.). É o que também aponta o estudo de Battistella et al. (2012) na formulação de estratégias de significado. Segundo os autores, a criação de significados não deve ocorrer apenas através dos produtos, mas nos "building blocks", ou seja, em toda a estrutura de uma empresa, equilibrando significados novos com os significados já existentes em seus produtos e serviços.

Entende-se que uma vez que um produto comunica em todas as categorias, ao pensar em novas proposições de significados, todas as ações relacionadas com o produto, como por exemplo, as campanhas promocionais, deverão ser coerentes com a proposta inicial do produto. Com esta proposta, o designer deverá estar informado sobre todas as decisões que poderão influenciar a forma como será percebido o produto final. Pois todas as categorias irão interferir no valor percebido do produto pelo consumidor.

\section{CONSIDERAÇÕES FINAIS}

A inovação guiada pelo design ainda é um tema relativamente recente. Através de uma maior compreensão das possibilidades de significação dos produtos e em posse de informações relativas às percepções dos usuários, os designers poderão avaliar as maneiras mais efetivas de comunicar os atributos desejados e influenciar o poder de atração de um produto. Até agora, a grande maioria das discussões em torno da inovação guiada pelo design se baseia na análise posterior de estudos de caso em design, ao invés de propor ferramentas ou métodos que auxiliem na proposição de novos significados.

Neste estudo foram discutidos alguns autores que indicam algumas maneiras de inovar na significação de produtos e foi sugerida uma categorização para essas significações. Seja através de uma análise histórica, ou da análise de ambientes socioculturais específicos ou mais abrangentes, percebe-se que os significados são dinâmicos e mudam também conforme o contexto.

Novas metodologias ainda estão sendo estudadas para propor produtos com novos significados ou de como sugerir novos significados em produtos já existentes, 


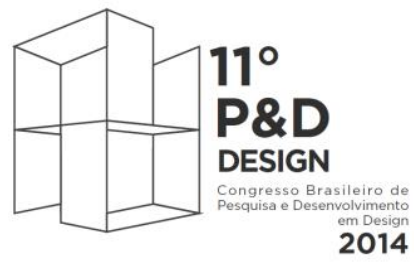

Gramado - RS

De 30 de setembro a 2 de outubro de 2014

sem que seja necessária uma total reformulação do produto, mas a decisão do direcionamento dos esforços para a inovação nas categorias aqui especificadas dependerá da estratégia a ser adotada por cada empresa. Em resumo, recomenda-se buscar o entendimento e o alinhamento das categorias de significados para a elaboração de estratégias mais coesas e consistentes.

\section{REFERÊNCIAS}

BAHA, Ehsan; et al. Retracing an evolution of meaning of design-driven innovation. 2013b. DeSForM- Design and Semantics of Form and Movement. Eindhoven University of Technology, 2013a.

BAHA, Ehsan; et al. Servitization of products as an approach for design-driven innovation. 2013b. Disponível em:<www.academia.edu/5903578/Servitization_of Products_as_an_Approach_for_Design-Driven_Innovation>. Acesso em: $10 \mathrm{fev} .2014$.

BATTISTELLA, Cinzia; BIOTTO, G.; de TONI, A. From design-driven innovation to meaning strategy. 2012. Journal of Management History.

BRASIL, L.; RITTO, A.C.A. Design e gestão de organizações. Anais P\&D Design 2000, Novo Hamburgo, RS, 29 out. A 01 nov. 2000.

BOABAID, Paula P. A indústria de joias no Brasil: posicionamento estratégico de uma micro-empresa. Dissertação (Mestrado em Administração). Rio de Janeiro: faculdades Ibmec, 2006.

BORJA DE MOZOTA, Brigitte; COSTA, Filipe C. X. da; KLÖPSCH, Cássia. Gestão do Design: usando o design para construir valor de marca e inovação corporativa. Porto Alegre: Bookman, 2011.

BÜRDEK, Bernhard E. Design: história teoria e prática do design de produtos. Trad. Freddy Van Camp. São Paulo: Blucher, 2010.

DONG, Andy. Design $x$ Innovation. 5th International Congress of International Association of Societies of Design Research (IASDR 2013). Tokyo: Japan: 5th International Congress of International Association of Societies of Design Research, 2013.

HANSEN-HANSEN, Erik. Learning from (luxury) fashion: entrepreneurship and design-led innovation. In: Leading Innovation Through Design: 2012 International design Management Research Conference. Aug. 8-9 2012, Boston, MA, USA.

KOTLER, Philip; KARTAJAYA, Hermawan; SETIAWAN, Iwan. Marketing 3.0: as forças que estão definindo o novo marketing centrado no ser humano. Rio de Janeiro: Elsevier, 2010. 


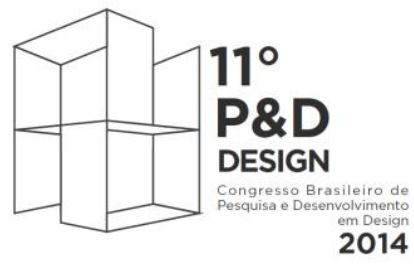

Gramado - RS

De 30 de setembro a 2 de outubro de 2014

KOTLER, Philip; KELLER, Kevin Lane. Administração de Marketing. São Paulo: Prentice Hall, 2006.

HANSEN-HANSEN, Erik. Learning from (luxury) fashion: entrepreneurship and design-led innovation. In: Leading Innovation Through Design: 2012 International design Management Research Conference. Aug. 8-9 2012, Boston, MA, USA.

KOTLER, Philip; KARTAJAYA, Hermawan; SETIAWAN, Iwan. Marketing 3.0: as forças que estão definindo o novo marketing centrado no ser humano. Rio de Janeiro: Elsevier, 2010.

KOTLER, Philip; KELLER, Kevin Lane. Administração de Marketing. São Paulo: Prentice Hall, 2006.

KRIPPENDORFF, Klaus; BUTTER, Reinhart. Product semantics: exploring the symbolic qualities of form. Departmental papers (ASC) University of Pennsylvania, 1984.

KRIPPENDORFF, Klaus. Product semantics: a triangulation and four design theories. Departmental papers (ASC) University of Pennsylvania, 1990.

KYFFIN, Steven; GARDIEN, Paul. Navigating the innovation matrix: an approach to design-led innovation. International Journal of design, 3(1), 57-69, 2009.

LINDAHL, Ingela; GRUNDSTRÖM, Christina. New product development in design-led organizations: insights from the Swedish furniture manufacturing industry. In: Leading Innovation Through Design: 2012 International design Management Research Conference. Aug. 8-9 2012, Boston, MA, USA.

MUTLU, B.; ER, A. Design Innovation: historical and theoretical perspectives on product innovation by design. Proceedings of the $5^{\text {th }}$ European Academy of Design Conference. 2013.

NORMAN, Donald; VERGANTI, Roberto. Incremental and radical innovation: design research versus technology and meaning change. Submitted to Design Issues. 2012.

NIEMEYER, Lucy. Elementos de semiótica aplicados ao design. Rio de Janeiro: $2 A B$, 2013.

RAMPINO, Lucia. The Innovation Pyramid: a categorization of the innovation phenomenon in the product-design field. International Journal of Design, 5(1), 3-16, 2011.

UTTERBACK, James. Design-inspired innovation. Singapore: World Scientific Publishing Company, 2007. 


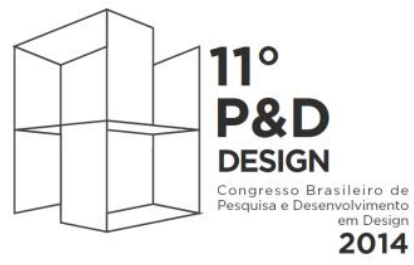

VERGANTI, Roberto. Design-driven innovation: mudando as regras da competição: a inovação radical do significado de produtos. São Paulo: Canal Certo, 2012a.

Design-Driven Innovation: como criar produtos com significados que deixarão as pessoas apaixonadas. Revista Infopaper. SENAI São Paulo Design, n.4, 2012b.

VERGANTI, Roberto; ÖBERG, Äsa. Interpreting an envisioning - a hermeneutic framework to look ar radical innovation of meanings. Industrial Marketing Management, v.42, n.1, Jan 2013, pp.86-95.

VIEIRA, Gabriel. Design e inovação: projeto orientado para o Mercado e centrado no usuário. Revista Convergências, n.4, 2007. Disponível em:<http://convergências.esart.ipcb.pt/artigo/58>. Acesso: 05/01/14. WALSH, Vivien; ROY, R.; BRUCE, M.; POTTER, S. Winning by design: technology, product design and international competitiveness. Design Innovation Group. Oxford: Blackwell, 1992. 